\title{
Cryptotanshinone induces cell cycle arrest and apoptosis through the JAK2/STAT3 and PI3K/Akt/ NFKB pathways in cholangiocarcinoma cells
}

This article was published in the following Dove Press journal:

Drug Design, Development and Therapy

I5 June 2017

Number of times this article has been viewed

\author{
Fayong $\mathrm{Ke}^{1,2, *}$ \\ Zheng Wang ${ }^{1,2, *}$ \\ Xiaoling Song ${ }^{1,2}$ \\ Qiang $\mathrm{Ma}^{\mathrm{l}, 2}$ \\ Yunping $\mathrm{Hu}^{2}$ \\ Lin Jiang ${ }^{2}$ \\ Yijian Zhang ${ }^{2}$ \\ Yingbin Liu ${ }^{1,2}$ \\ Yong Zhang' \\ Wei Gong ${ }^{1,2}$
}

'Department of General Surgery, Xinhua Hospital, School of Medicine, Shanghai Jiao Tong University,

Shanghai, People's Republic of China;

${ }^{2}$ Institute of Biliary Disease Research, School of Medicine, Shanghai Jiao

Tong University, Shanghai, People's

Republic of China

*These authors contributed equally to this work
Correspondence: Wei Gong

Department of General Surgery, Xinhua Hospital, Shanghai Jiao Tong University,

School of Medicine, 1665 Kongjiang

Road, Shanghai 200092, People's

Republic of China

$\mathrm{Tel}+86$ I36 5I8I 9806

Email 1365I8I9806@I63.com
Background: Cholangiocarcinoma (CCA) is the most common biliary tract malignancy in the world with high resistance to current chemotherapies and extremely poor prognosis. The main objective of this study was to investigate the inhibitory effects of cryptotanshinone (CTS), a natural compound isolated from Salvia miltiorrhiza Bunge, on CCA both in vitro and in vivo and to explore the underlying mechanisms of CTS-induced apoptosis and cell cycle arrest.

Methods: The anti-tumor activity of CTS on HCCC-9810 and RBE cells was assessed by 3-(4,5-dimethylthiazol-2-yl)-2,5-diphenyl-tetrazolium bromide (MTT) assay and colony forming assays. Cell cycle changes were detected by flow cytometric analysis. Apoptosis was detected by annexin V/propidium iodide double staining and Hoechst 33342 staining assays. The efficacy of CTS in vivo was evaluated using a HCCC-9810 xenograft model in athymic nude mice. The expression of key proteins involved in cell apoptosis and signaling pathway in vitro was analyzed by Western blot analysis.

Results: CTS induced potent growth inhibition, S-phase arrest, apoptosis, and colony-forming inhibition in HCCC-9810 and RBE cells in a dose-dependent manner. Intraperitoneal injection of CTS $(0,10$, or $25 \mathrm{mg} / \mathrm{kg})$ for 4 weeks significantly inhibited the growth of HCCC-9810 xenografts in athymic nude mice. CTS treatment induced S-phase arrest with a decrease of cyclin A1 and an increase of cyclin D1 protein level. Bcl-2 expression was downregulated remarkably, while Bax expression was increased after apoptosis occurred. Additionally, the activation of JAK2/ STAT3 and PI3K/Akt/NFKB was significantly inhibited in CTS-treated CCA cells.

Conclusion: CTS induced CCA cell apoptosis by suppressing both the JAK2/STAT3 and $\mathrm{PI} 3 \mathrm{~K} / \mathrm{Akt} / \mathrm{NF} \mathrm{KB}$ signaling pathways and altering the expression of Bcl-2/Bax family, which was regulated by these two signaling pathways. CTS may serve as a potential therapeutic agent for CCA.

Keywords: cholangiocarcinoma, cryptotanshinone, apoptosis, JAK2/STAT3, PI3K/Akt/NFkB

\section{Introduction}

In recent years, the incidence of cholangiocarcinoma (CCA) has significantly increased, especially in South America and Asia, making it the second most common primary liver tumor and the most common biliary tract malignancy in the world. ${ }^{1} \mathrm{CCA}$ is a slow progression cancer with no specific symptoms, and most CCA patients usually present with advanced incurable stage. Surgical resection is the only potentially curative option for CCA. ${ }^{2,3}$ However, not all CCA patients are good candidates for curative surgery, and complete surgical resection is often followed by local recurrence or metastases with a overall 5-year survival rate of 5\%-10\%. ${ }^{4,5}$ Moreover, high drug resistance usually lowers the efficacy of chemotherapy drugs. ${ }^{6}$ Therefore, novel 
therapeutic strategies and/or potential effective anticancer agents against this malignancy are urgently needed.

Cryptotanshinone (CTS, Figure 1), is one of the main effective ingredients isolated from traditional Chinese medical herb Salvia miltiorrhiza Bunge (Danshen in Chinese), which is commonly used in traditional oriental medicine for the treatment of cardiovascular diseases, hepatitis, diabetes, and chronic hepatic failure. ${ }^{7,8}$ Recently, more attention has been paid to its anticancer effect. Studies have shown that CTS can inhibit the growth of certain kinds of tumor cells or induce tumor cell apoptosis, including leukemia, breast cancer, prostate cancer, and lung cancer..$^{9-12}$ Nevertheless, CTS did not affect the survival of noncancerous cells, such as human peripheral blood lymphocytes, ${ }^{9}$ human embryonic kidney HEK293 cells, ${ }^{13}$ and mouse embryonic fibroblasts. ${ }^{14}$ CTS-induced cancer cell death was attributed to cell cycle arrest, ${ }^{15,16}$ apoptosis, $, 9,12,17$ and suppression of STAT3 signaling. ${ }^{9,11-13,18}$ However, the effect of CTS on human CCA cells has not been previously investigated.

The Janus kinase/signal transducers and activators of transcription (JAK/STAT) pathway are the principal signaling mechanism for a wide array of cytokines and growth factors. ${ }^{19}$ JAK2, a member of JAK family of non-receptor protein tyrosine kinases, regulates signaling via multiple cytokine receptors. ${ }^{20}$ The activation of STAT3 has been linked with the proliferation, survival, invasion, and angiogenesis of a variety of human cancer cells. In addition, the phosphatidylinositol 3-kinase (PI3K)/Akt pathway is involved in the regulation of many cell processes including proliferation and survival. ${ }^{21} \mathrm{PI} 3 \mathrm{~K}$ is a dimeric enzyme composed of an inhibitory/regulatory (p85) subunit and a catalytic (p110) subunit. The p85 subunit anchors to erbB receptor docking sites,

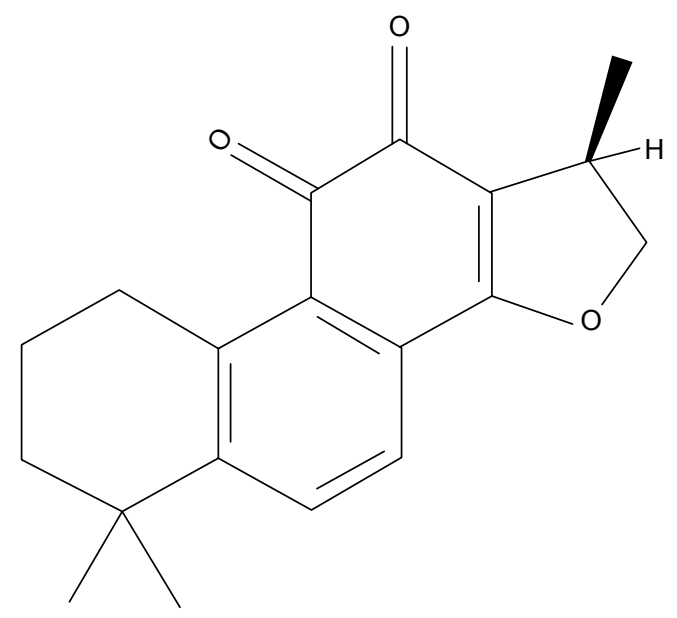

Figure I Chemical structure of cryptotanshinone. whereas the p110 subunit is responsible for the phosphorylation and activation of the protein serine/threonine kinase $\mathrm{Akt}^{22,23}$ which plays a major role in cell survival, apoptosis, and oncogenesis regulation. Akt can also activate NF $\kappa B$ pathway via phosphorylation and activation of molecules in the NFKB pathway, which plays an important role in the control of cell growth, differentiation, and apoptosis. ${ }^{24}$ CTS has been previously shown to inhibit the activity of STAT signaling in certain cancer cells. ${ }^{13,18}$ Herein, we first reported that CTS induced cell death through both JAK2/STAT3 and $\mathrm{PI} 3 \mathrm{~K} / \mathrm{Akt} / \mathrm{NF}$ B pathways.

In this study, we investigated the effects of CTS-induced growth inhibition, cell cycle arrest, and apoptosis in CCA cells in vitro and in vivo, and the molecular mechanisms responsible for these effects, which could provide experimental evidence for the potential application of CTS as a new natural anti-tumor medicine for CCA.

\section{Materials and methods Materials}

CTS, an orange-brown powder, was purchased from SigmaAldrich (St Louis, MO, USA). CTS is a cell-permeable diterpene quinone and its chemical name is 1,2,6,7,8,9hexahydro-1,6,6-trimethyl-(R)-phenanthro(1,2-b)furan10,11-dione (CAS registry number: 35825-57-1), with a molecular formula of $\mathrm{C}_{19} \mathrm{H}_{20} \mathrm{O}_{3}$, a molecular weight of 296.36 , and a melting point of 184 . To prepare working solutions, CTS was dissolved in 100\% dimethyl sulfoxide (DMSO) to create a stock solution $(50 \mathrm{mmol} / \mathrm{L})$ and stored at $-20^{\circ} \mathrm{C}$. CTS was further diluted in culture media for all in vitro experiments. The control cells were treated with the same amount of vehicle alone. The final DMSO concentration did not exceed $0.5 \%$ and did not have any detectable effect on cell growth or cell death. 3-(4,5Dimethylthiazol-2-yl)-2,5-diphenyl-tetrazolium bromide (MTT), Hoechst 33342, annexin V-FITC, and propidium iodide (PI) were purchased from Sigma Chemical Co. (St Louis, MO, USA).

\section{Cell lines and cell culture}

Two human CCA cell lines HCCC-9810 and RBE were purchased from the Cell Bank of Type Culture Collection of Chinese Academy of Sciences (Shanghai, People's Republic of China). HCCC-9810 and RBE cells were cultured in Roswell Park Memorial Institute 1640 medium (Gibco, Waltham, MA, USA). The media for the cell lines were supplemented with 10\% fetal bovine serum (Gibco), $100 \mu \mathrm{g} / \mathrm{mL}$ streptomycin, and $100 \mathrm{U} / \mathrm{mL}$ penicillin (Hyclone, 
Logan, UT, USA) and maintained at $37^{\circ} \mathrm{C}$ in a humidified atmosphere with $5 \% \mathrm{CO}_{2}$.

\section{Cell viability assay}

The viability of cells treated with CTS was measured by the MTT assay. During the logarithmic growth phase, cells were collected and seeded in 96-well plates at a density of $3 \times 10^{3}$ cells/well and cultured. After $12 \mathrm{~h}$ of incubation, the cells were treated with CTS at serial concentrations $(0,10$, $20,30,40$, and $50 \mu \mathrm{mol} / \mathrm{L}$ ) for 24,48 , and $72 \mathrm{~h}$. After treatment, $20 \mu \mathrm{L}$ of MTT solution $(5 \mathrm{mg} / \mathrm{mL})$ was added to each well and the cells were then incubated at $37^{\circ} \mathrm{C}$ for $4 \mathrm{~h}$. The culture medium was then replaced with $100 \mu \mathrm{L}$ of DMSO. The absorbance of the solution at $490 \mathrm{~nm}$ was measured with a microplate reader (Bio-Tek, Winooski, VT, USA). The results represent the average of 5 parallel samples. The cell viability ratio was calculated by the following formula: cell viability $(\%)=$ average absorbance of treated group/average absorbance of control group $\times 100 \%$.

\section{Colony forming assay}

HCCC-9810 and RBE cells were plated into a 6-well culture plate $(700$ cells/well) and allowed to adhere for $12 \mathrm{~h}$ before treatment. After adherence, cells were treated with CTS $(0,2$, 4 , and $8 \mu \mathrm{mol} / \mathrm{L}$ ). After $48 \mathrm{~h}$, the CTS-containing medium was removed, and the cells were allowed to form colonies in complete medium for 14 days. Then, the colonies were fixed with a solution of acetic acid and methanol (1:3) for $15 \mathrm{~min}$, stained with $5 \%$ Giemsa (Sigma-Aldrich) for $30 \mathrm{~min}$, and counted manually. Digital images of stained single clones were observed under a microscope (Leica, Wetzlar, Germany). The total number of colonies ( $>50$ cells/colony) was counted manually.

\section{Cell cycle analysis}

HCCC-9810 and RBE cells were treated with CTS $(0,10$, 20 , and $40 \mu \mathrm{mol} / \mathrm{L}$ ) for $48 \mathrm{~h}$. Cells were then harvested by trypsinization, washed twice in cold PBS, and fixed in $70 \%$ ethanol at $4^{\circ} \mathrm{C}$ overnight. After fixation, the cells were washed and resuspended in cold PBS and then treated with staining buffer (PBS containing $1 \mathrm{mg} / \mathrm{mL}$ PI and $10 \mathrm{mg} / \mathrm{mL}$ RNase A; Sigma-Aldrich) at $37^{\circ} \mathrm{C}$ in the dark for $30 \mathrm{~min}$. The samples were analyzed with a flow cytometer and the data were analyzed using Cell Quest acquisition software (BD Biosciences, San Diego, CA, USA).

\section{Cell apoptosis assay}

The cells were treated with CTS $(0,10,20$, and $40 \mu \mathrm{mol} / \mathrm{L})$ for $48 \mathrm{~h}$. After washing twice with cold PBS, the cells were resuspended at a density of $1 \times 10^{6}$ cells $/ \mathrm{mL}$. Then, $100 \mu \mathrm{L}$ of binding buffer containing $2.5 \mu \mathrm{L}$ of annexin V-FITC and $1 \mu \mathrm{L}$ of $100 \mu \mathrm{g} / \mathrm{mL}$ PI was added to these cells and incubated for $30 \mathrm{~min}$ in the dark. Finally, the samples were analyzed by a flow cytometer (BD Biosciences).

\section{Detection of morphological apoptosis by Hoechst 33342 staining}

HCCC-9810 and RBE cells were treated with CTS $(0,10,20$, and $40 \mu \mathrm{mol} / \mathrm{L}$ ) for $48 \mathrm{~h}$, then washed with PBS, and fixed in methanol:acetic acid (3:1) for $15 \mathrm{~min}$ at room temperature. The fixed cells were washed with PBS and stained with $5 \mu \mathrm{g} / \mathrm{mL}$ Hoechst 33342 for $10 \mathrm{~min}$. Then, the morphological changes in the Hoechst 33342-stained nuclei of cells were observed using a fluorescence microscope (Leica).

\section{Western blot analysis}

The cells were treated with CTS $(0,10,20$, and $40 \mu \mathrm{mol} / \mathrm{L})$ for $48 \mathrm{~h}$. Then, the cells were harvested and lysed in a RIPA buffer (Beyotime Institute of Biotechnology, Shanghai, People's Republic of China) and protease inhibitor (Roche Applied Science, Indianapolis, IN, USA). Protein concentration was determined using the BCA Protein Assay (Beyotime Institute of Biotechnology). Protein samples were separated using sodium dodecyl sulfate polyacrylamide gel electrophoresis and transferred to polyvinylidene difluoride membranes (Millipore, Bedford, MA, USA). Membranes were then incubated with respective primary antibodies, followed by HRP-conjugated secondary antibodies. Proteins were visualized using the Gel Doc 2000 (Bio-Rad Laboratories Inc., Hercules, CA, USA). Glyceraldehyde 3-phosphate dehydrogenase (GAPDH) antibody was used as an internal control for whole cell lysates. The primary antibodies used were JAK2, STAT3, PI3K, Akt, NFkB, Bax, Bcl-2, cleaved caspase $3 / 9$, cleaved poly(ADP-ribose) polymerase (PARP), cyclin A1, cyclin B1, and cyclin D1. All the antibodies were purchased from Cell Signaling Technology.

\section{In vivo xenograft model}

Male athymic nude mice (4 weeks old with an initial body weight of $20 \pm 2 \mathrm{~g}$ ) were obtained from Shanghai SLAC Laboratory Animal Co., Ltd. (Shanghai, People's Republic of China). The animals were acclimatized at a temperature of $25^{\circ} \mathrm{C} \pm 2{ }^{\circ} \mathrm{C}$ and a relative humidity of $70 \% \pm 5 \%$ under natural light/dark conditions for 1 week and were allowed free access to food and water. All animal treatments were performed in strict accordance with international ethical guidelines and the National Institutes of Health Guide for the Care and Use of 
Laboratory Animals. The animal experiments were approved by the Institutional Animal Care and Use Committee of Shanghai Jiao Tong University.

Exponentially growing HCCC-9810 cells were resuspended in serum-free culture medium (at a density of $1 \times 10^{6}$ cells in $0.2 \mathrm{~mL}$ ) and injected subcutaneously into the right axilla of recipient mice. After 1 week of implantation, tumor-bearing mice were randomly divided into three groups (control, 10, and $25 \mathrm{mg} \mathrm{kg}$ ), with six animals in each group. CTS was administered to the mice in the latter two treatment groups by intraperitoneal injection every 2 days at 10 or $25 \mathrm{mg} / \mathrm{kg}$, respectively. Control animals received intraperitoneal injections of vehicle (10\% DMSO and 90\% PBS). Tumor volume was measured using calipers and estimated according to the following formula: tumor volume $\left(\mathrm{mm}^{3}\right)=\left(\mathrm{L} \times \mathrm{W}^{2}\right) / 2$, where $\mathrm{L}$ and $\mathrm{W}$ represent the length and width of the tumor, respectively. After 4 weeks of treatment, all mice were killed, and tumors were dissected and weighed.

\section{Statistical analysis}

All data and results were confirmed in at least 3 independent experiments. The results of each experiment are presented as mean $\pm \mathrm{SD}$ or as indicated. Student's $t$-test was used to compare the difference between treated groups and their controls using SPSS version 19.0 software (IBM Corporation). A $P$-value of less than 0.05 was considered significant for all tests.

\section{Results \\ CTS inhibits the proliferation of CCA cells}

To determine the effects of CTS on cell proliferation, we investigated the role of CTS on proliferative activities of HCCC-9810 and RBE cell lines by the MTT assay. The results indicated that CTS significantly diminished the proliferative activities of both cancer cell lines in a time- and dose-dependent manner compared with the control group (Figure 2A). Additionally, the two tumor cell lines showed different sensitivity to CTS. HCCC-9810 cells were more sensitive to CTS than RBE cells. The $\mathrm{IC}_{50}$ values (the concentration of drug inhibiting $50 \%$ of the cells) of HCCC9810 and RBE cells at $48 \mathrm{~h}$ were around 15 and $20 \mu \mathrm{mol} / \mathrm{L}$, respectively. According to the viability curve, we choose 10 , 20 , and $40 \mu \mathrm{mol} / \mathrm{L}$ as the optimum concentration range for both cells in the following experiments.

\section{CTS inhibits colony formation in HCCC-98IO and RBE cells}

To investigate the independent growth of CCA cells, the ability of HCCC-9810 and RBE cells to form colonies in the presence of CTS was assessed by the flat plate colony forming assay. After being treated with CTS, the colonies of HCCC9810 and RBE cells were then stained by Giemsa. There were significant differences in photomicrographic photography. The density of colonies and the size of single colony of CCA cells in each group were gradually reduced in a concentrationdependent manner (Figure 2B). The results showed that CTS induced a dose-dependent decrease in colony formation. The number of colonies of CTS-treated HCCC-9810 and RBE cells was significantly lower than that in the control group. Moreover, statistical analysis demonstrated that the mean diameter of the single colony in the control was larger than that in the CTS-treated group (Figure 2C). The findings support the fact that CTS may exert a significant influence on HCCC-9810 and RBE cell proliferation.

\section{CTS induces S-phase arrest in HCCC- 9810 and RBE cells}

To determine whether the effects of CTS on the proliferation of CCA cells are mediated by inhibition of cell cycle progression, the cell cycle phases of treated cells were analyzed by flow cytometry. The results showed that CTS induced cell cycle arrest at S-phase in a dosedependent manner in both HCCC-9810 and RBE cell lines (Figure 3A). Generally, the cycle is divided into G0/G1 (DNA presynthetic phase), S (DNA synthesis phase), and G2/M (DNA postsynthetic phase) according to the content of DNA..$^{25}$ The number of HCCC-9810 and RBE cells in the G0/G1 phase was significantly decreased. The number of HCCC-9810 and RBE cells in the S phase was significantly increased (Figure 3B). There was a statistically significant difference $(P<0.05)$. These results by flow cytometry for cell cycle analysis indicated that both the HCCC-9810 and RBE cells might occur the DNA synthesis phase ( $\mathrm{S}$ phase) cell block with a dose-dependent effect.

Moreover, we also assessed the levels of cycle-related proteins by Western blot analysis (Figure 3C). Different cyclins were expressed in each stage of the cell cycle..$^{26,27}$ CTS treatment resulted in a dose-dependent decrease in the expression of S-phase-related protein cyclin A1 and increase in the expression of G0/G1-phase-related protein cyclin D1 in both HCCC-9810 and RBE cells, while the change in expression of G2/M-phase-related protein cyclin B1 of HCCC-9810 and $\mathrm{RBE}$ cells is not simultaneously related to the change of CTS concentration in a dose-dependent manner. There was a statistically significant difference compared to the control $(P<0.05)$. Cyclin B1 presents during the late $\mathrm{S}$ and $\mathrm{G} 2$ phases of the mammalian cell cycle, and it becomes activated during the late $\mathrm{G} 2$ phase. ${ }^{28}$ It indicated that after treatment the CCA 
A

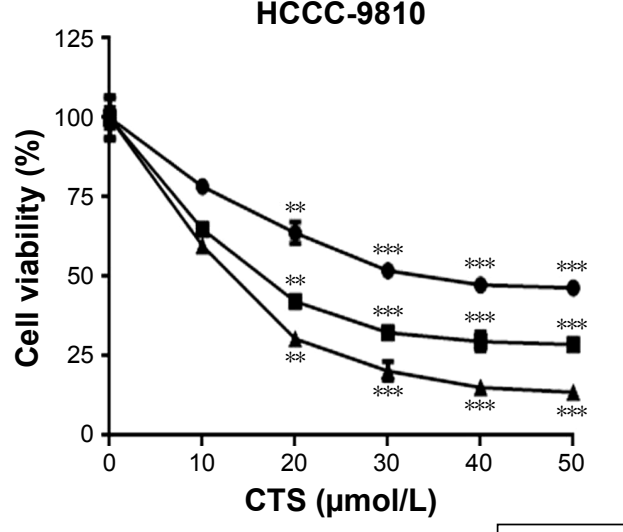

RBE

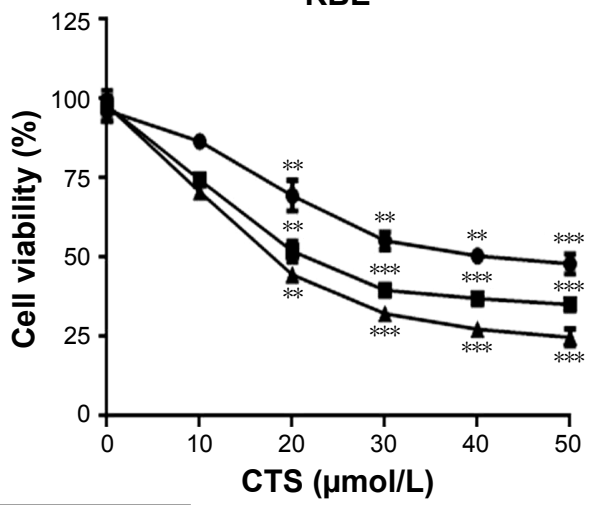

B
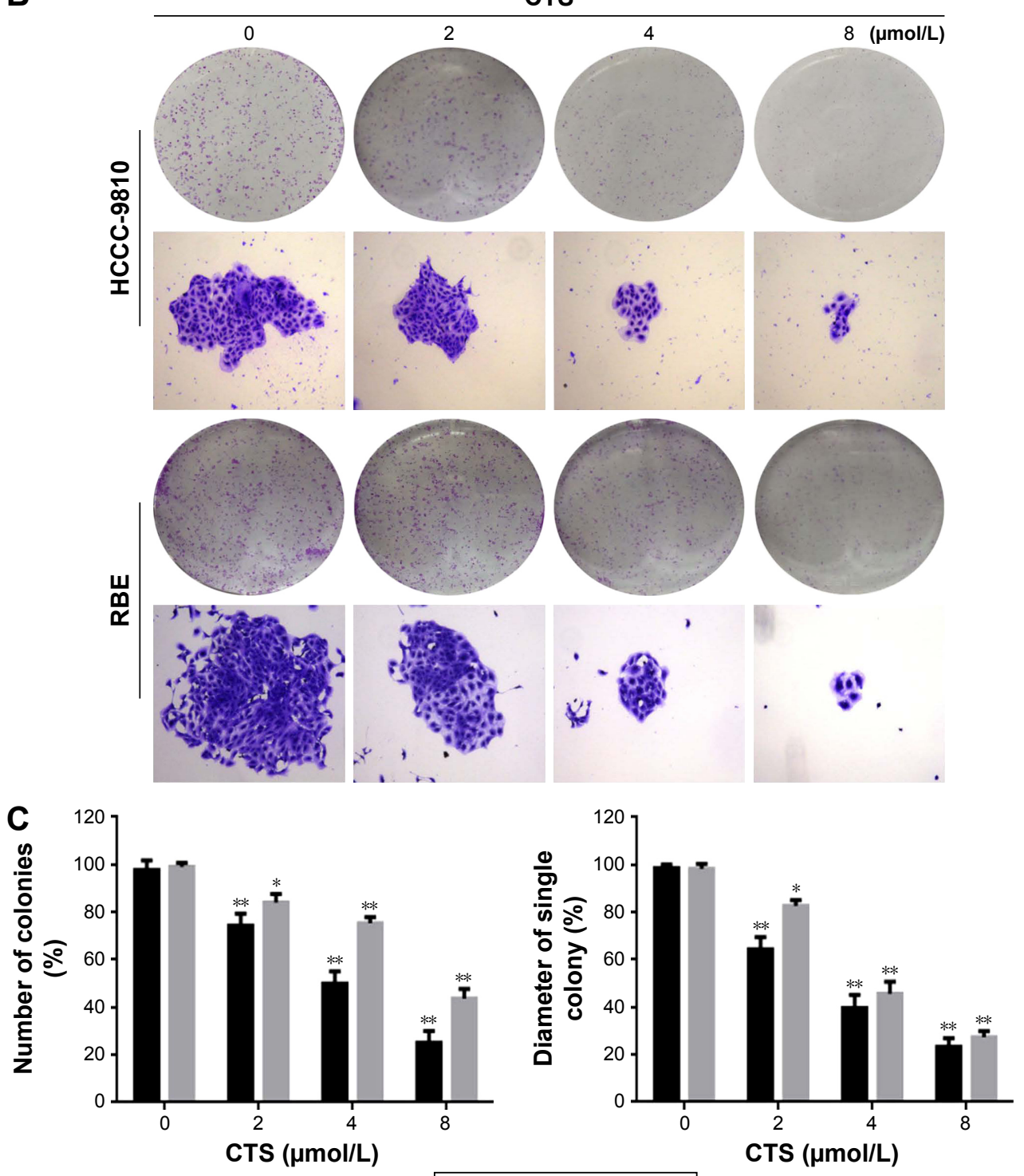

HCCC-9810 RBE

Figure 2 CTS inhibits the proliferation and colony formation of CCA cells.

Notes: (A) HCCC-98IO and RBE cells were treated with various concentrations of CTS for 24, 48, and $72 \mathrm{~h}$. Cell viability was examined by MTT assay. (B) HCCC-98I0 and RBE cells were treated with CTS $(0,2,4$, and $8 \mu \mathrm{mol} / \mathrm{L})$ for $48 \mathrm{~h}$. Then, the medium was replaced with fresh medium, and the cells were cultured for another I4 days. The colonies were then stained by Giemsa. There were significant differences in photomicrographic photography. (C) The numbers of colonies and the diameter of a single colony of CCA cells were counted. The data are expressed as the mean \pm SD of 3 replicate experiments. Significant differences from the control are indicated by $* P<0.05$, $* * P<0.0 \mathrm{I}$, and $* * * P<0.00 \mathrm{I}$. Abbreviations: CTS, cryptotanshinone; CCA, cholangiocarcinoma; MTT, 3-(4,5-dimethylthiazol-2-yl)-2,5-diphenyl-tetrazolium bromide. 
A

CTS (48 h)
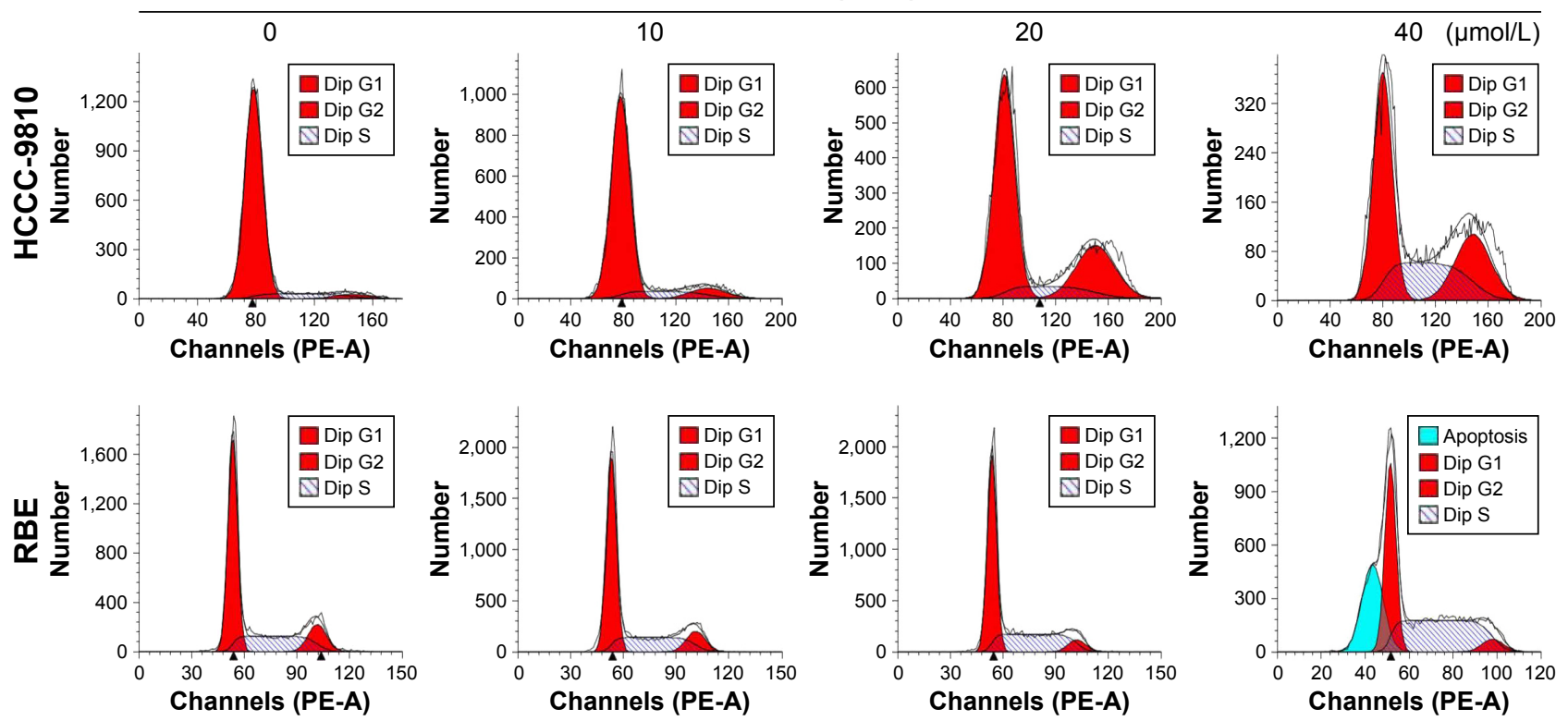

B

HCCC-9810 + CTS ( $\mu \mathrm{mol} / \mathrm{L})$
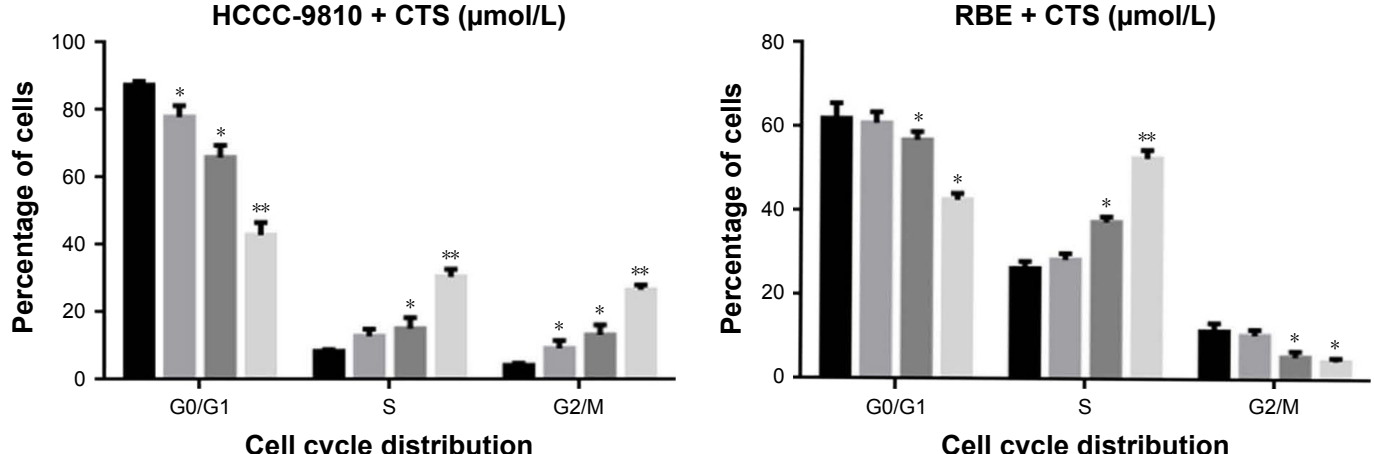

\begin{tabular}{|l|l|l|l}
\hline $0 \mu \mathrm{mol} / \mathrm{L}$ & $10 \mu \mathrm{mol} / \mathrm{L}$ & $20 \mu \mathrm{mol} / \mathrm{L}$ & $40 \mu \mathrm{mol} / \mathrm{L}$
\end{tabular}

C

CTS (48 h)
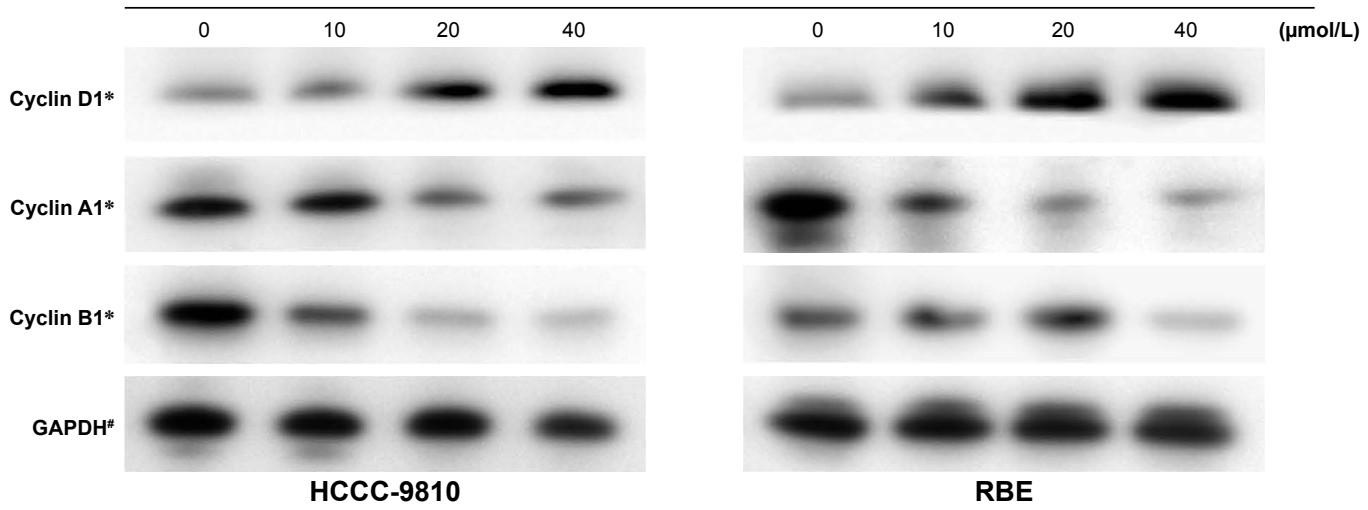

Figure 3 CTS induces cell cycle arrest at $S$ phase and regulates the expression of cell cycle-related proteins in CCA cells.

Notes: HCCC-9810 and RBE cells were treated with CTS $(0,10,20$, and $40 \mu \mathrm{mol} / \mathrm{L})$ for $48 \mathrm{~h}$. (A) The cell cycle distribution of the treated cells was evaluated by flow cytometry. (B) The percentage of cells in the G0/GI, S, and G2/M phases of the cell cycle are shown. (C) The expression levels of cyclin DI, cyclin AI, and cyclin BI were measured by Western blot analysis, and GAPDH was used as a loading control. Results are representative of 3 independent experiments. $* P<0.05$, $* * P<0.01$, and ${ }^{*} P>0.05$ vs the control group. Abbreviations: CTS, cryptotanshinone; CCA, cholangiocarcinoma; GAPDH, glyceraldehyde 3-phosphate dehydrogenase.

cells could smoothly pass through the G1 period, and block in $\mathrm{S}$ phase to $\mathrm{G} 2$ phase transition, also called $\mathrm{S}$ phase arrest, which corresponded to cell cycle analysis by flow cytometry (Figure 3A and B).
These results showed that cell cycle arrest in $\mathrm{S}$ phase also accounts for the antiproliferative effect of CTS in both cell lines possibly by disturbing the expression of cell cycle distribution proteins and related regulators. 


\section{CTS induces apoptosis in HCCC-9810 and RBE cells}

We used annexin V/PI staining and flow cytometry to examine whether CTS-induced growth inhibition was a result of apoptosis and the results are shown in Figure 4. Exposure of phosphatidylserine on the surface of cells is an early event in the onset of apoptosis, which has a strong binding affinity for annexin V in the presence of calcium. By contrast, PI can detect necrotic cells due to its ability to permeate damaged cell membranes. After HCCC-9810 and RBE cells were incubated with different concentrations of CTS, cells were stained with Annexin V-FITC and PI, which can assess the early apoptotic and late apoptotic cell population. In the scatter plot of double variable flow cytometry (Figure 4A), the regional meaning is as follows: Q1 for the damaged cells, Q2 for the late apoptotic cells, Q3 for living cells, and Q4 for early apoptotic cells.

As assessed by flow cytometry, CTS treatment induced a dose-dependent increase in both early and late stage apoptosis of HCCC-9810 and RBE cells, and there was a significant statistical difference compared with the control group $(P<0.05)$. CTS at a concentration of $40 \mu \mathrm{mol} / \mathrm{L}$ had a more significant apoptosis-inducing effect when compared to the number of apoptotic cells in the control group (Figure 4B). These indicated that apoptotic pathway played an important role in the proliferation inhibition of CTS on HCCC-9810 and RBE cells.

\section{Effect of CTS on the cell morphology}

Apoptosis was also confirmed by examining the nuclear morphology of CTS-treated cells. Morphological changes in the apoptotic cells were revealed by Hoechst 33342 staining, as shown in Figure 5. The cells in the control group were round and stained weak homogeneous blue, whereas CTS-treated cells showed obvious chromatin condensation and fragmentation. Moreover, the numbers of apoptotic nuclei containing condensed chromatin increased significantly as the CTS concentration
A

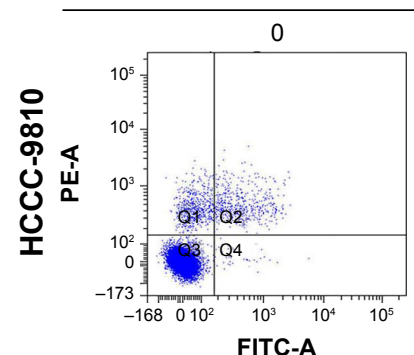

FITC-A

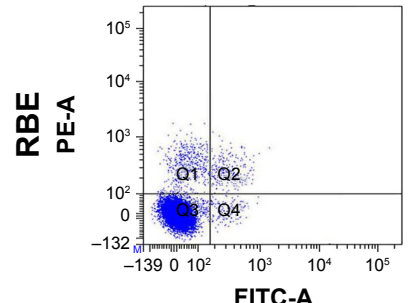

FITC-A
CTS (48 h)
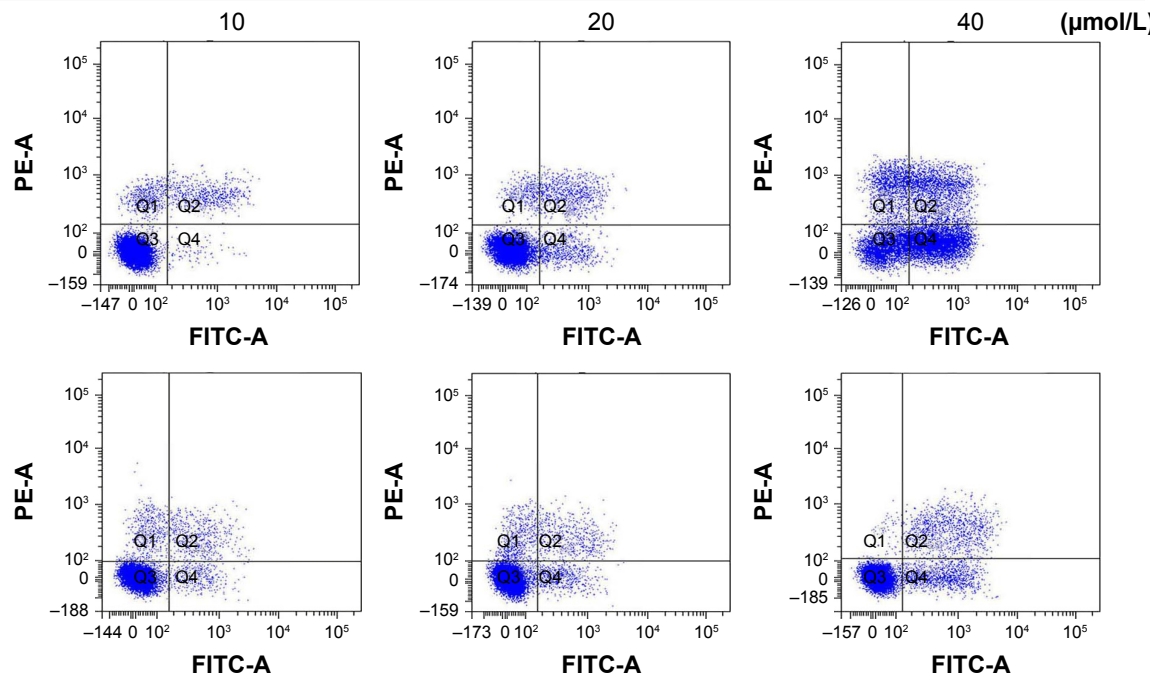

B
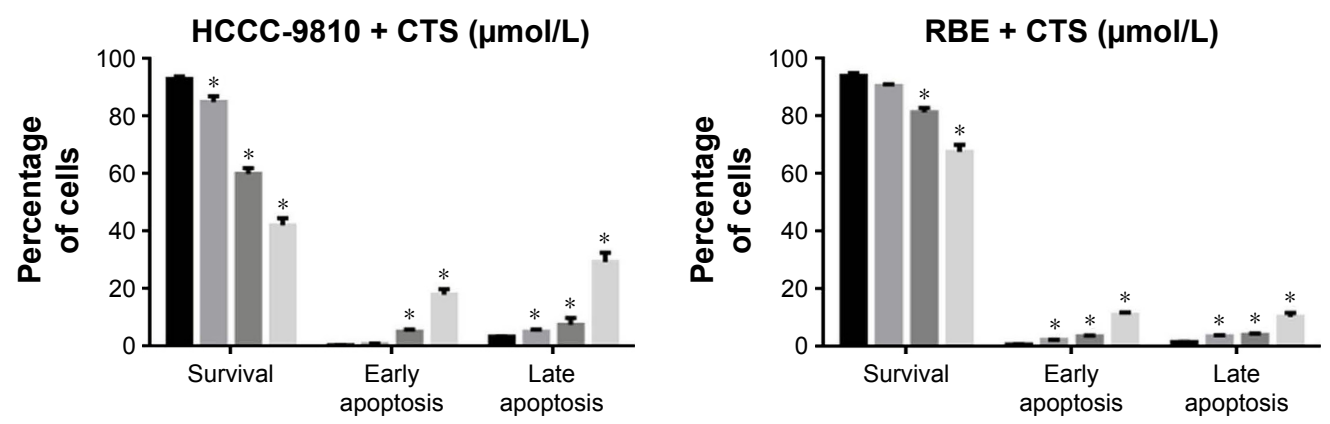

$0 \mu \mathrm{mol} / \mathrm{L} \quad 10 \mu \mathrm{mol} / \mathrm{L} \quad 20 \mu \mathrm{mol} / \mathrm{L} \quad 40 \mu \mathrm{mol} / \mathrm{L}$

Figure 4 CTS induces apoptosis in CCA cells.

Notes: HCCC-98I0 and RBE cells were treated with CTS (0, 10, 20, and $40 \mu \mathrm{mol} / \mathrm{L})$ for $48 \mathrm{~h}$. (A) CTS-treated CCA cells were stained with annexin V-FITC/PI and analyzed by flow cytometry. (B) Percentages of survival and early and late apoptotic cells are presented as mean \pm SD ( $n=3$ ). Results shown are representative data from 3 independent experiments. $* P<0.05$ vs the control group.

Abbreviations: CTS, cryptotanshinone; CCA, cholangiocarcinoma; PI, propidium iodide. 


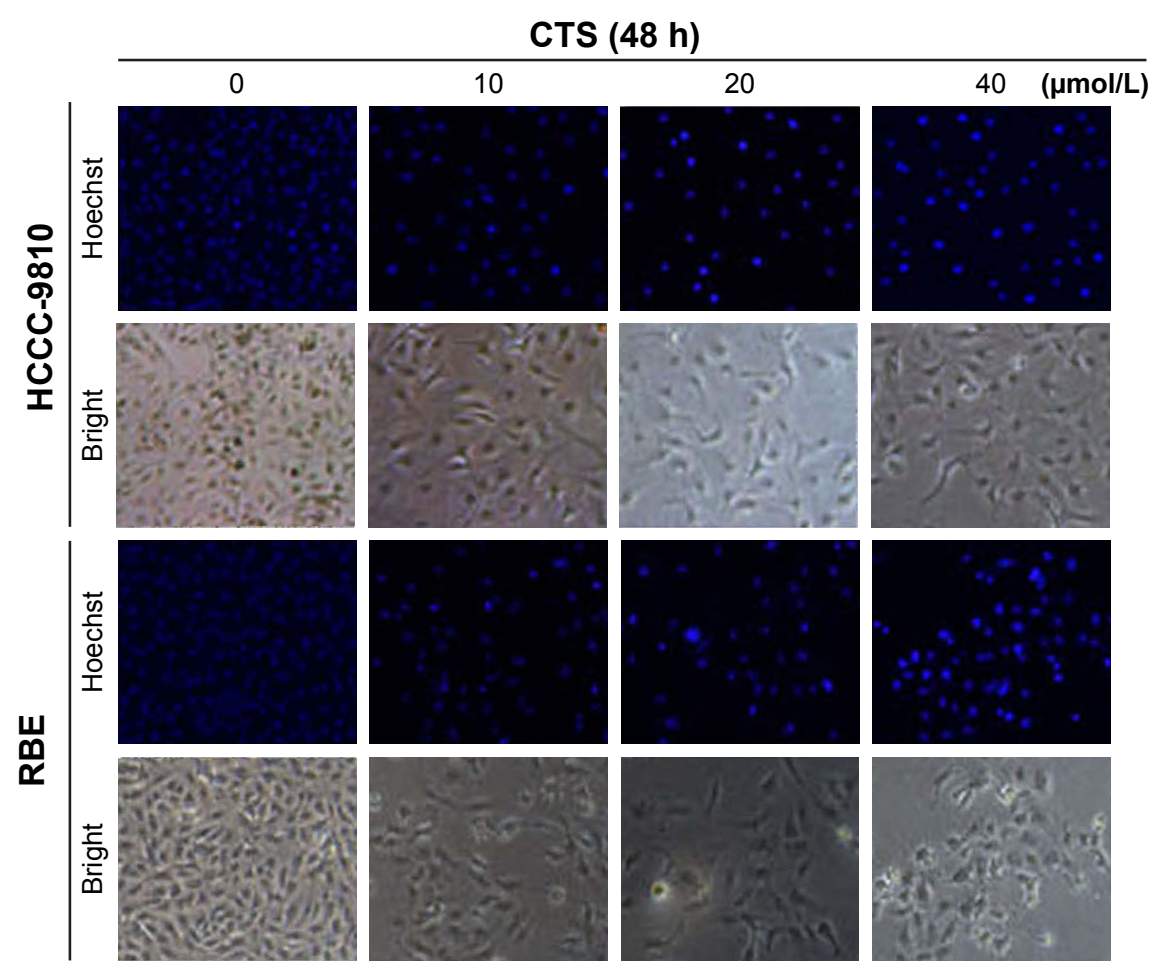

Figure 5 Effect of CTS on the cell morphology.

Notes: Apoptotic nuclear morphology changes induced by CTS (0, 10, 20, and $40 \mu \mathrm{mol} / \mathrm{L})$ treatment for $48 \mathrm{~h}$ were observed by Hoechst 33342 staining in HCCC-98I 0 and RBE cells. Images were visualized by fluorescent microscopy.

Abbreviation: CTS, cryptotanshinone.

increased. Based on these morphologic changes, CTS appeared to cause apoptosis of HCCC-9810 and RBE cells.

\section{CTS alters the expression of proteins in HCCC-98I 0 and RBE cells}

To investigate the mechanistic basis of proliferation inhibitory effects of CTS, we next examined its effect on the expression of key proteins involved in cell apoptosis and signaling pathway by Western blot analysis.

\section{CTS regulates the expression of caspase and $\mathrm{Bcl}-2$ family members}

It is well known that proteins in the caspase and Bcl-2 family, caspase-3/9 and Bcl-2/Bax, play critical roles in the apoptotic process. Just as shown in Figure 6A, our data revealed that CTS increased the amount of Bax, cleaved caspase-3, cleaved caspase-9, and cleaved PARP, but decreased the amount of Bcl-2 in a dose-dependent manner. Furthermore, we found that CTS treatment resulted in a dose-dependent decrease in the ratio of Bcl-2/Bax in protein levels (Figure 6B). It suggested that $\mathrm{CTS}$ could regulate the apoptosis-related proteins to induce apoptosis in CCA cells. These may be responsible, at least in part, for the apoptotic tendency of CTS-treated HCCC-9810 and RBE cells.

\section{CTS blocked the JAK2/STAT3 and $\mathrm{PI} 3 \mathrm{~K} / \mathrm{Akt} / \mathrm{NFKB}$ signaling}

Abnormal JAK/STAT and PI3K/Akt/NFkB signaling pathways are involved in the pathogenesis of several cancers including apoptosis. ${ }^{19-21}$ Among the signaling pathway proteins, we observed a dose-dependent reduction in the protein levels of JAK2 phosphorylation, STAT3 phosphorylation, PI3K (p110), AKT phosphorylation, and NFKB, whereas the expression of total JAK2, STAT3, and Akt was not changed (Figure 7). It suggested that CTS could block the JAK2/STAT3/PI3K/Akt/NFKB signaling by inhibiting the phosphorylation of key proteins.

According to the results of Western blot analysis, we could come to a conclusion of the proposed signaling pathway activated by CTS in CCA cells, which is shown in Figure 8. The Bcl-2 family protein, Bcl-2, is known to be a downstream target of the STAT pathway. ${ }^{29}$ The phosphorylated Akt can activate several apoptosis-regulating proteins, including the pro-apoptotic Bcl-2 family protein Bax. ${ }^{30}$ The signaling pathways induced by activated JAKs include not only the STAT signaling pathway but also the PI3K/Akt signaling pathway, which play a significant role in mitogenic and cell survival. ${ }^{31,32}$ These findings demonstrate that CTS alters the expression of proteins involved in the regulation of cell 
A

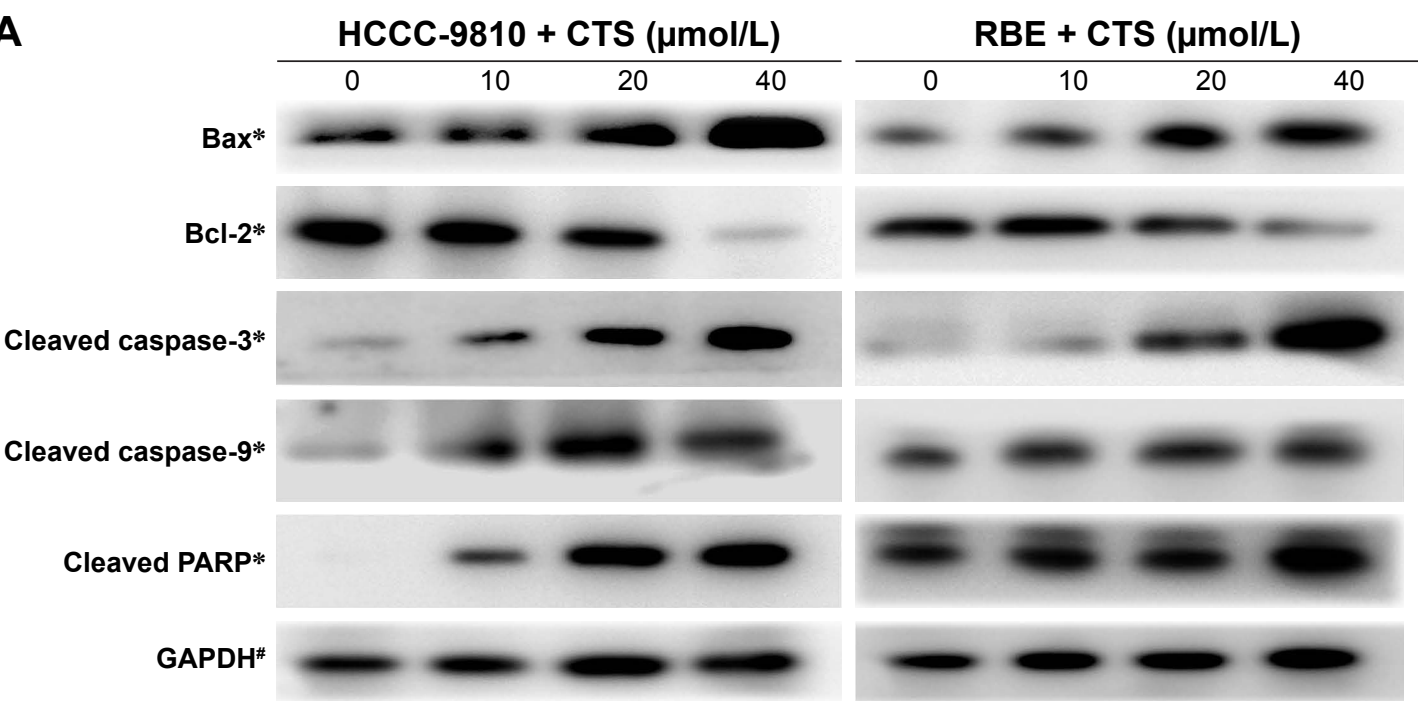

B

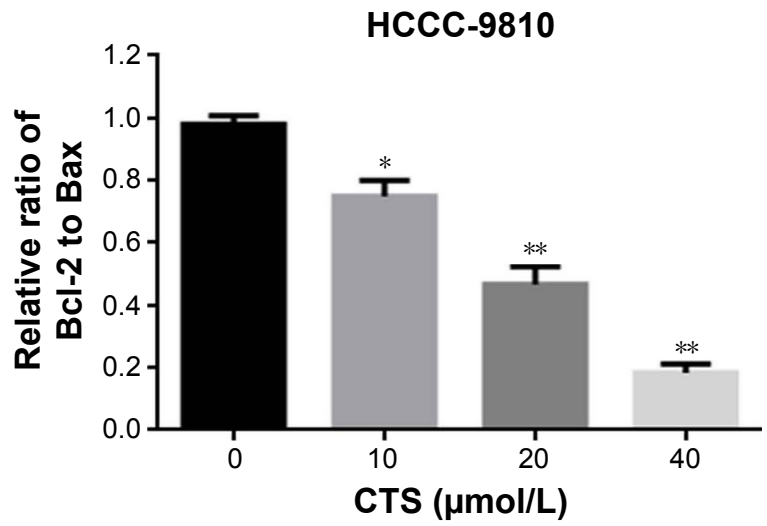

RBE

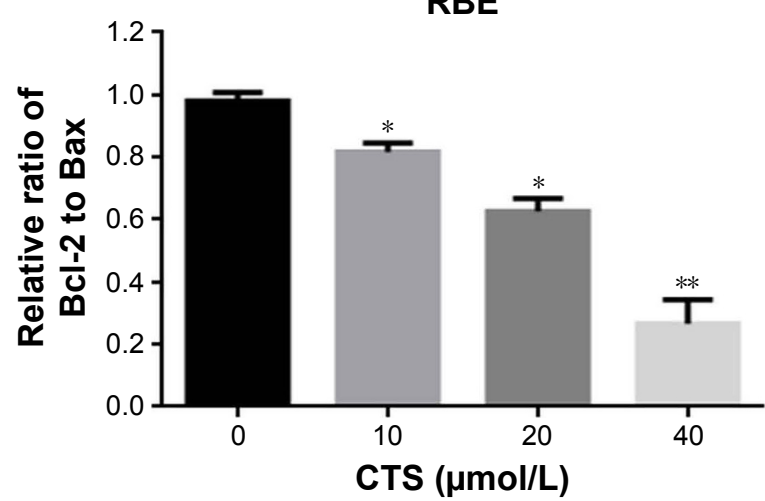

Figure 6 CTS alters the expression of apoptosis-related proteins in CCA cells.

Notes: HCCC-98I0 and RBE cells were treated with CTS (0, 10, 20, and $40 \mu \mathrm{mol} / \mathrm{L})$ for $48 \mathrm{~h}$, and cell lysates were prepared. (A) The expression levels of apoptosis-related proteins, cleaved caspase-3, cleaved caspase-9, cleaved PARP, Bax, and Bcl-2, were detected by Western blot analysis. GAPDH was used as a loading control. (B) The Bcl-2/ Bax ratio was evaluated by the band density compared with the control, and the results are expressed as mean $\pm S D$. $* P<0.05$, $* * P<0.01$, and $\# P>0.05$ vs the control group. Abbreviations: CTS, cryptotanshinone; CCA, cholangiocarcinoma; PARP, poly(ADP-ribose) polymerase; GAPDH, glyceraldehyde 3-phosphate dehydrogenase.

apoptosis and signaling pathway to confer its proliferation inhibitory effect.

\section{CTS inhibits xenograft growth in vivo}

It was reported that CTS has no effect on bodyweight loss or systemic toxicity through intragastric or intraperitoneal administration at the maximal tolerant dose in mice. ${ }^{33}$ To further investigate the CTS effect on tumor growth in vivo, we intraperitoneally injected vehicle (10\% DMSO and 90\% PBS) or two increasing doses of CTS into nude mice with subcutaneous HCCC-9810 tumor xenografts. The tumors removed from these animals are shown in Figure 9A, and their final mean weights and volumes changing over the weeks are provided in Figure 9B and C. Our results showed that tumor growth in the two treatment groups was significantly inhibited in a dose-response manner compared with that in the control group. The appearance of the tumors was in agreement with the statistical analysis of tumor volume and weight data $(P<0.05)$, which showed that CTS treatment significantly inhibited tumor growth. Our results indicated that the tumor growth in nude mice injected with HCCC-9810 cells was significantly reduced in a dose-dependent manner after treatment with CTS compared with mice injected with vehicle alone.

\section{Discussion}

CTS, (also named cryptotanshinon or called tanshinone C), is a cell-permeable diterpene quinone, derived from the roots of Salvia miltiorrhiza Bunge. The chemical structure of CTS has a phenanthrenequinone structure, the phenanthrene ring of which can bind to the DNA in the tumor cells. The interaction of phenanthrene ring and cell DNA can lead to increased intracellular free radicals, which results in the inhibition of the synthesis of tumor cell DNA and finally 


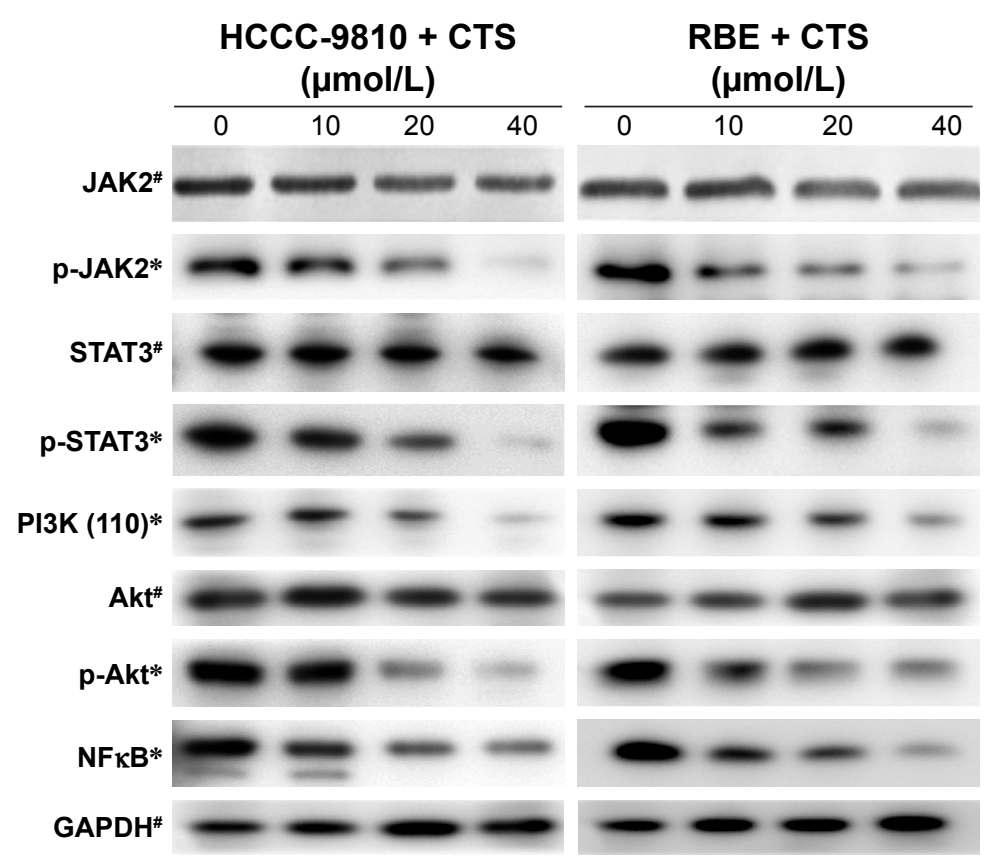

Figure 7 CTS alters the expression of JAK2/STAT3/PI3K/Akt/NFKB signaling proteins.

Notes: HCCC-9810 and RBE cells were treated with CTS $(0,10,20$, and $40 \mu \mathrm{mol} / \mathrm{L})$ for $48 \mathrm{~h}$, and cell lysates were prepared. The expression levels of signaling pathway proteins (total and phosphorylation of JAK2/STAT3/Akt, PI3K [PI I0] and NFKB) were detected by Western blot analysis. GAPDH was used as a loading control. *P $<0.05$ and ${ }^{\#} P>0.05$ vs the band density of the control group.

Abbreviations: CTS, cryptotanshinone; GAPDH, glyceraldehyde 3-phosphate dehydrogenase.

inhibition of tumor cell proliferation. ${ }^{34,35}$ Studies have shown that CTS possesses antiproliferative and apoptotic activities against certain types of human cancers..$^{9-14}$ However, little is known concerning the inhibitory effect of CTS on CCA

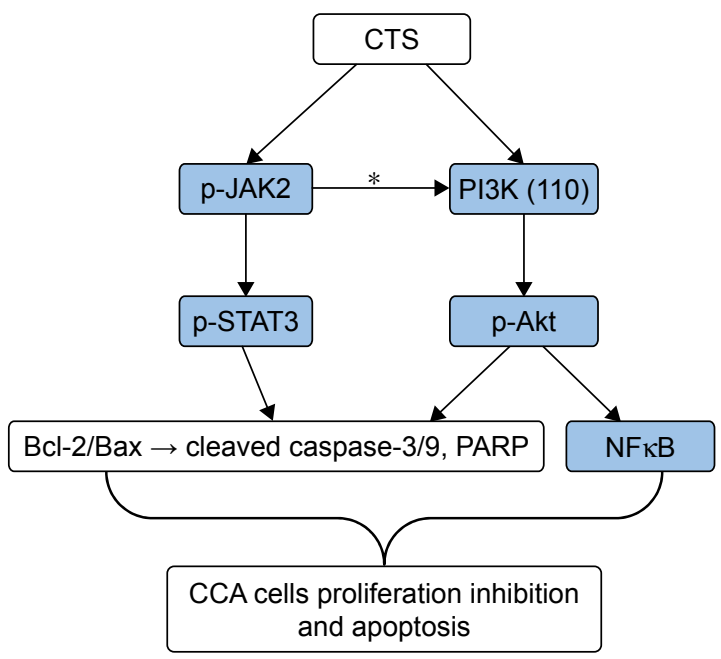

Figure $\mathbf{8}$ The proposed signaling pathway activated by CTS in CCA cells.

Notes: The potential mechanism of apoptosis induced by CTS in HCCC-9810 and RBE cells. Sustained suppression of JAK2/STAT3 and PI3K/Akt/NFKB signaling pathways by CTS results in deregulation of downstream gene (Bcl-2 family, Caspases family) expression and should contribute to apoptosis progression in CCA cells. *According to $\mathrm{Yu}$ and Jove ${ }^{31}$ and Rane and Reddy, ${ }^{32}$ JAKs play an essential role in mediating the activation of both STAT and PI3K/Akt signaling.

Abbreviations: CTS, cryptotanshinone; CCA, cholangiocarcinoma; PARP, poly (ADP-ribose) polymerase. cells and its underlying mechanisms. In our study, for the first time, we examined the anti-cancer activity and potential mechanisms of CTS on human CCA cell lines. We chose the human intrahepatic CCA cell lines of HCCC-9810 and RBE cells, which were established by tumor tissue of Asian patients with CCA. Both cell lines have similar organizational origin and culture characteristics.

Our study indicated that treatment of CCA cells with CTS could induce inhibition. The data from the MTT assays showed that CTS could inhibit the growth of HCCC-9810 and RBE cells in a time- and dose-dependent manner (Figure 2A). Both the concentration and incubation time affected the degree and extent of cytotoxicity of CTS on CCA cells. The colony forming assay showed similar results (Figure 2B). The predominant mode of cell death in these cells was apoptosis, as determined by annexin V-FITC/PI staining (Figure 4), which is characteristic in the morphology of Hoechst 33342-stained cells (Figure 5), and cell cycle arrest studies (Figure 3A). Consistent with these in vitro results, treatment of HCCC-9810 xenografts in athymic nude mice with CTS for 4 weeks significantly decreased the growth of the xenografts (Figure 9). These results provided strong evidence in support of the notion that CTS has potent anti-cancer effects against CCA in vitro and in vivo. 

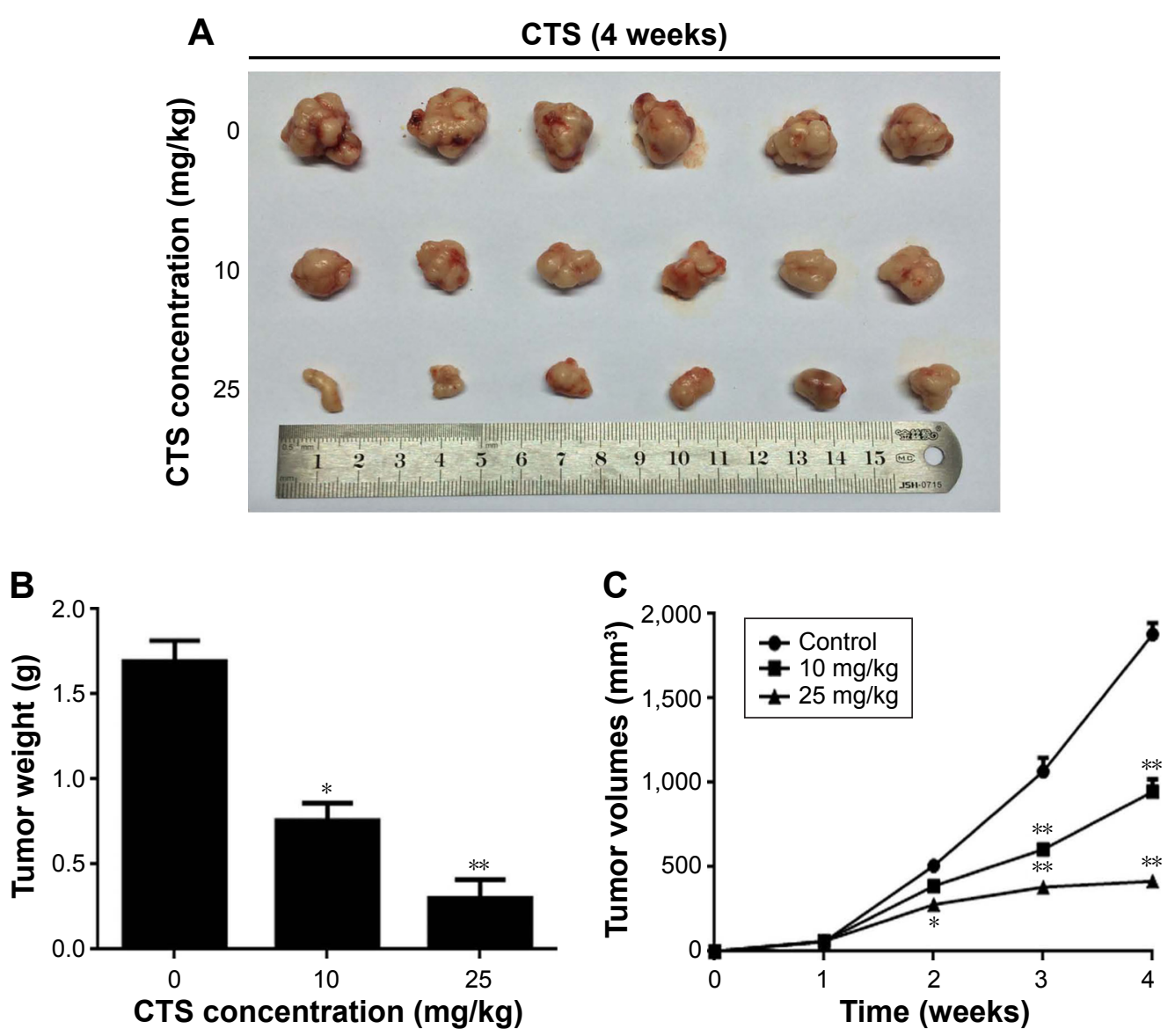

Figure 9 CTS suppressed the growth of HCCC-9810 cells in athymic nude mice.

Notes: HCCC- 9810 cells were subcutaneously injected into the right axilla of the nude mice. The mice were then administered $0.2 \mathrm{~mL}$ of vehicle (I0\% DMSO and $90 \%$ PBS) or CTS $(0,10$, and $25 \mathrm{mg} / \mathrm{kg})$ intraperitoneally every 2 days for up to 4 weeks. (A) Photo of 6 representative tumors excised from the animals of each group are presented to show the sizes of the resulting tumors. (B) Tumors were excised from the animals and weighed. (C) Tumor dimensions were periodically measured using calipers over the 4 weeks. Significant differences from the control are indicated by $* P<0.05$ and $* * P<0.0$ I.

Abbreviations: CTS, cryptotanshinone; DMSO, dimethyl sulfoxide.

To examine the mechanism of CTS-induced inhibition of cell survival, we performed cell cycle distribution experiment in the presence of CTS. As suggested by our cell cycle analysis data, CTS caused HCCC-9810 and RBE cells to arrest at the $\mathrm{S}$ phase (Figure 3), which may result from the downregulation of cyclin A1 and upregulation of cyclin D1 in a dose-dependent manner. For the expression of G2/M-phase-related protein cyclin B1, we observed that the HCCC-9810 cells of G2/M phase were increased with the concentration, which was consistent with the change that cyclin B1 of HCCC-9810 cells was decreased significantly in a concentration-dependent manner. However, the change of $\mathrm{G} 2 / \mathrm{M}$ phase and cyclin B1 of RBE cells is not related to the change of CTS concentration obviously in a dose-dependent manner. Cyclin B1 presents during the late $\mathrm{S}$ and $\mathrm{G} 2$ phases of the mammalian cell cycle, and it becomes activated during the late $\mathrm{G} 2$ phase. ${ }^{28}$ It indicated that both CTS-treated HCCC-9810 and RBE cells could smoothly pass through the
G1 period, but get blocked in S phase to $\mathrm{G} 2$ phase transition, also called S-phase arrest, which corresponded to cell cycle analysis by flow cytometry.

These results also indicated that there were some differences in the effects of CTS on the cycle-related pathway proteins in different cell lines (HCCC-9810 and RBE cells), which is because that progression through various phases of cell cycle is a tightly regulated process involving various cycle-related proteins or regulators. There are cell cycle proteins, checkpoint regulatory proteins, DNA replication/ damage proteins, mitosis related proteins and so on, and they interacted with each other. ${ }^{26-28}$ Our study found that CTS had a regulatory effect on the cell cycle of CCA cells, which was that CTS could induce S-phase arrest of both HCCC-9810 and RBE cells, but the specific cycle pathway and the target proteins need to be further explored.

Following cell cycle arrest, cells may either undergo repair or enter the apoptotic pathway to maintain cellular 
integrity. ${ }^{36}$ Generally, there are two major apoptosis pathways: the death-receptor-induced extrinsic pathway and the mitochondria-apoptosome-mediated intrinsic pathway. ${ }^{37}$ The prime inducers of apoptotic pathways are pro-apoptotic and anti-apoptotic Bcl-2 family proteins and caspases. Both the extrinsic pathway and the mitochondria-mediated intrinsic apoptosis pathway ultimately require activated caspases, which is a family of cysteine proteases and play essential roles in apoptosis. ${ }^{38}$ Among them, caspase- 8 or caspase- 9 can activate caspase-3, which is one of the most important executioner caspases. Caspase-3 cleaves several cellular proteins, including the PARP protein, resulting in morphological changes and DNA fragmentation that eventually lead to apoptosis. ${ }^{39}$ In addition, $\mathrm{Bcl}-2$ family proteins, including Bax, Bad, Bid, Bcl-2, and Bcl-xL, located on the mitochondrial membrane can alter the permeability of the mitochondrial membrane and trigger the release of cytochrome $\mathrm{c}$ or caspases, thus activating the post-mitochondrial caspase cascade and leading to apoptotic cell death. ${ }^{40,41}$ In the present study, we observed the downregulation of Bcl-2/Bax expression and the activation of cleaved caspase-3, caspase-9, and PARP following CTS treatment in HCCC-9810 and RBE cells (Figure 6A), indicating that the mitochondrial pathway was involved in CTS-induced apoptosis.

The pro-apoptotic members Bax and Bad induce the release of cytochrome $\mathrm{c}$ from the mitochondria within cells, whereas anti-apoptotic Bcl-2 and Bcl-xL promote cell survival by preventing cytochrome c release from the mitochondria. ${ }^{40,41}$ A low ratio of Bcl-2 to Bax can induce caspase activation, the release of cytochrome c, and subsequently apoptosis. It is also used to evaluate the occurrence and degree of apoptosis. ${ }^{42}$ As for the caspases family, the pro-apoptotic proteins caspase $3 / 9$, which can regulate the cleavage of PARP, are activated when the ratio of Bcl-2/ Bax is decreased. In our study, the upregulation of Bax and downregulation of Bcl-2 were observed in CCA cells after being treated with different concentrations of CTS, and the ratio of Bcl-2/Bax also decreased in a dose-dependent manner (Figure 6B), which could contribute to the activation of proapoptotic protein caspases thus resulting in cell apoptosis.

The disoriented regulation of apoptosis is considered to be one of the main contributors to cancer development. The JAK/STAT and PI3K/Akt/NFKB signaling pathways play a significant role in cell proliferation, tumorigenesis, and apoptosis. ${ }^{19-21}$ However, the molecular mechanism by which CTS regulates JAK2/STAT3 and PI3K/Akt/NFkB signaling pathways and contributes to apoptosis has not been clarified in CCA cells. In the present study, we found a dose-dependent reduction in the protein levels of PI3K (p110) and NFKB and phosphorylation of JAK2/STAT3/Akt, whereas the expression of total JAK2/STAT3/Akt was not changed obviously (Figure 7). It suggested that CTS could inhibit the phosphorylation of key proteins in the signaling pathways. Our data also suggest that CTS induces apoptosis via the suppression of both the JAK2/STAT3 and PI3K/Akt/ NFKB signaling pathways concomitantly in CCA cells, which was consistent with the proven suggestion that JAKs play an essential role in mediating activation of both constitutive STAT and PI3K/Akt signaling.

Furthermore, JAK2/STAT3 signaling was shown to be directly involved in cell proliferation and survival by upregulating the expression of anti-apoptotic proteins, such as Bcl-2 and Bcl-xL. ${ }^{30}$ In addition, activated Akt can also phosphorylate several Bcl-2 family proteins (eg, proapoptotic proteins Bax and Bad) at the same time of activation of the NFKB pathway. These data suggest that CTS-mediated inactivation of Akt in CCA cells is associated with a reduction in the expression of Bax, which is consistent with our results of Western bolt analysis. According to the findings of the present study, we could come to a conclusion that CTSmediated upregulation of Bax expression and downregulation of Bcl-2 expression in CCA cells are mediated via JAK2/ STAT3- and PI3K/Akt-dependent pathways. Thus, sustained suppression of JAK/STAT and PI3K/Akt/NFKB signaling pathways by CTS results in deregulation of downstream gene (Bcl-2 family, Caspases family) expression and should contribute to apoptosis progression in CCA cells (Figure 8).

CTS has been commonly used in oriental medicine for the treatment of cardiovascular diseases and hepatitis. ${ }^{7,8}$ Studies have shown that CTS did not affect the survival of noncancerous cells, ${ }^{9,13,14}$ and it has also been reported to show no systemic toxicity in the in vivo studies. ${ }^{33}$ Therefore, CTS could be considered as a promising anticancer drug. CCA is a highly malignant neoplasm that carries a poor prognosis and lacks effective therapy. Moreover, high drug resistance of CCA cells usually lowers the efficacy of chemotherapy drugs. Studies have shown that targeted therapy on JAK2/ STAT3 or PI3K/Akt pathway could be effective for several cancers, such as endometrial cancer and ovarian cancer. ${ }^{43-45}$ Researchers have reported that the resistance of CCA to chemotherapy could be related to the PI3K/Akt signaling, and that targeted inhibition on PI3K/Akt signaling pathway may increase sensitivity to chemotherapeutic agents. ${ }^{46}$ In addition, it has been reported that CTS could reverse chemotherapy resistance in colon cancer and lung cancer cells. ${ }^{47,48}$ Since we have found that CTS induces CCA cell 
apoptosis through suppression of the JAK2/STAT3 and $\mathrm{PI} 3 \mathrm{~K} / \mathrm{Akt} / \mathrm{NF} \mathrm{KB}$ signaling pathways concomitantly, CTS may be able to serve as a potential therapeutic agent targeting the JAK2/STAT3/PI3K/Akt signaling pathway for CCA. However, further studies are certainly needed for the application of CTS in clinical trials for CCA.

\section{Conclusion}

In summary, our study showed that CTS is a potent growth inhibitor of CCA cells in vitro and in vivo. Growth inhibition of CCA by CTS was time and dose dependent and related to S-phase arrest. CTS also caused a marked increase in apoptosis, which was determined by characteristic morphological changes and increased numbers of apoptotic cells. Furthermore, we demonstrated that CTS induced apoptosis by suppressing both the JAK2/STAT3 and PI3K/Akt/NFKB signaling pathways concomitantly and altering the expression of Bax and Bcl-2, which were regulated by these two signaling pathways in CCA cells. We therefore believe that CTS could be a novel promising agent for the treatment of CCA.

\section{Acknowledgments}

This work was supported by the National Natural Science Foundation of China (81672404) and the Shanghai Municipal Education Commission - Gaofeng Clinical Medicine Grant Support to Wei Gong (2015). The authors thank Dr Yuanyuan Ye (Institute of Biliary Disease Research, School of Medicine, Shanghai Jiao Tong University, People's Republic of China) for helping revise the manuscript.

\section{Disclosure}

The authors report no conflicts of interest in this work.

\section{References}

1. Bergquist A, von Seth E. Epidemiology of cholangiocarcinoma. Best Pract Res Clin Gastroenterol. 2015;29(2):221-232.

2. Khan SA, Thomas HC, Davidson BR, Taylor-Robinson SD. Cholangiocarcinoma. Lancet. 2005;366(9493):1303-1314.

3. Razumilava N, Gores GJ. Cholangiocarcinoma. Lancet. 2014;383(9935): 2168-2179.

4. Khuntikeo N, Pugkhem A, Titapun A, Bhudhisawasdi V. Surgical management of perihilar cholangiocarcinoma: a Khon Kaen experience. $J$ Hepatobiliary Pancreat Sci. 2014;21(8):521-524.

5. Cidon EU. Resectable cholangiocarcinoma: reviewing the role of adjuvant strategies. Clin Med Insights Oncol. 2016;10:43-48.

6. Shaib Y, El-Serag HB. The epidemiology of cholangiocarcinoma. Semin Liver Dis. 2004;24(2):115-125.

7. Zhou X, Chan SW, Tseng HL, et al. Danshensu is the major marker for the antioxidant and vasorelaxation effects of Danshen (Salvia miltiorrhiza) water-extracts produced by different heat water-extractions. Phytomedicine. 2012;19(14):1263-1269.

8. Jin Q, Jiang S, Wu YL, et al. Hepatoprotective effect of cryptotanshinone from Salvia miltiorrhiza in D-galactosamine/lipopolysaccharide-induced fulminant hepatic failure. Phytomedicine. 2014;21(2):141-147.
9. Kim JH, Jeong SJ, Kwon TR, et al. Cryptotanshinone enhances TNF- $\alpha-$ induced apoptosis in chronic myeloid leukemia KBM-5 cells. Apoptosis. 2011;16(7):696-707.

10. Li S, Wang H, Hong L, et al. Cryptotanshinone inhibits breast cancer cell growth by suppressing estrogen receptor signaling. Cancer Biol Ther. 2015;16(1):176-184.

11. Shin DS, Kim HN, Shin KD, et al. Cryptotanshinone inhibits constitutive signal transducer and activator of transcription 3 function through blocking the dimerization in DU145 prostate cancer cells. Cancer Res. 2009;69(1):193-202.

12. Man Y, Yang L, Zhang D, Bi Y. Cryptotanshinone inhibits lung tumor growth by increasing CD4+ T cell cytotoxicity through activation of the JAK2/STAT4 pathway. Oncol Lett. 2016;12(5):4094-4098.

13. Li W, Saud SM, Young MR, Colburn NH, Hua B. Cryptotanshinone, a Stat3 inhibitor, suppresses colorectal cancer proliferation and growth in vitro. Mol Cell Biochem. 2015;406(1-2):63-73.

14. Park IJ, Yang WK, Nam SH, et al. Cryptotanshinone induces G1 cell cycle arrest and autophagic cell death by activating the AMPactivated protein kinase signal pathway in HepG2 hepatoma. Apoptosis. 2014;19(4):615-628.

15. Chen W, Luo Y, Liu L, et al. Cryptotanshinone inhibits cancer cell proliferation by suppressing Mammalian target of rapamycin-mediated cyclin D1 expression and Rb phosphorylation. Cancer Prev Res (Phila). 2010;3(8):1015-1025.

16. Chen L, Zheng SZ, Sun ZG, et al. Cryptotanshinone has diverse effects on cell cycle events in melanoma cell lines with different metastatic capacity. Cancer Chemother Pharmacol. 2011;68(1):17-27.

17. Chen L, Wang HJ, Xie W, Yao Y, Zhang YS, Wang H. Cryptotanshinone inhibits lung tumorigenesis and induces apoptosis in cancer cells in vitro and in vivo. Mol Med Rep. 2014;9(6):2447-2452.

18. Lu L, Li C, Li D, et al. Cryptotanshinone inhibits human glioma cell proliferation by suppressing STAT3 signaling. Mol Cell Biochem. 2013;381(1-2):273-282.

19. Rawlings JS, Rosler KM, Harrison DA. The JAK/STAT signaling pathway. J Cell Sci. 2004;117(Pt 8):1281-1283.

20. Babon JJ, Lucet IS, Murphy JM, Nicola NA, Varghese LN. The molecular regulation of Janus kinase (JAK) activation. Biochem J. 2014; 462(1):1-13.

21. Lin HL, Yang MH, Wu CW, et al. 2-Methoxyestradiol attenuates phosphatidylinositol 3-kinase/Akt pathway-mediated metastasis of gastric cancer. Int J Cancer. 2007;121(11):2547-2555.

22. Yarden Y, Sliwkowski MX. Untangling the ErbB signalling network. Nat Rev Mol Cell Biol. 2001;2(2):127-137.

23. Cantley LC. The phosphoinositide 3-kinase pathway. Science. 2002; 296(5573):1655-1657.

24. Ozes ON, Mayo LD, Gustin JA, Pfeffer SR, Pfeffer LM, Donner DB. NF-kappaB activation by tumour necrosis factor requires the Akt serinethreonine kinase. Nature. 1999;401(6748):82-85.

25. Shaltiel IA, Krenning L, Bruinsma W, Medema RH. The same, only different - DNA damage checkpoints and their reversal throughout the cell cycle. J Cell Sci. 2015;128(4):607-620.

26. Bloom J, Cross FR. Multiple levels of cyclin specificity in cell-cycle control. Nat Rev Mol Cell Biol. 2007;8(2):149-160.

27. Woo RA, Poon RY. Cyclin-dependent kinases and $\mathrm{S}$ phase control in mammalian cells. Cell Cycle. 2003;2(4):316-324.

28. Porter LA, Donoghue DJ. Cyclin B1 and CDK1: nuclear localization and upstream regulators. Prog Cell Cycle Res. 2003;5:335-347.

29. Du W, Hong J, Wang YC, et al. Inhibition of JAK2/STAT3 signalling induces colorectal cancer cell apoptosis via mitochondrial pathway. J Cell Mol Med. 2012;16(8):1878-1888.

30. Pugazhenthi S, Nesterova A, Sable C, et al. Akt/protein kinase B upregulates Bcl-2 expression through cAMP-response element-binding protein. J Biol Chem. 2000;275(15):10761-10766.

31. Yu H, Jove R. The STATs of cancer - new molecular targets come of age. Nat Rev Cancer. 2004;4(2):97-105.

32. Rane SG, Reddy EP. Janus kinases: components of multiple signaling pathways. Oncogene. 2000;19(49):5662-5679. 
33. Xu D, Lin TH, Li S, et al. Cryptotanshinone suppresses androgen receptor-mediated growth in androgen dependent and castration resistant prostate cancer cells. Cancer Lett. 2012;316(1):11-22.

34. Chen W, Lu Y, Chen G, Huang S. Molecular evidence of cryptotanshinone for treatment and prevention of human cancer. Anticancer Agents Med Chem. 2013;13(7):979-987.

35. Wang AM, Sha SH, Lesniak W, Schacht J. Tanshinone (Salviae miltiorrhizae extract) preparations attenuate aminoglycoside-induced free radical formation in vitro and ototoxicity in vivo. Antimicrob Agents Chemother. 2003;47(6):1836-1841.

36. Chen CY, Hsu YL, Chen YY, Hung JY, Huang MS, Kuo PL. Isokotomolide A, a new butanolide extracted from the leaves of Cinnamomum kotoense, arrests cell cycle progression and induces apoptosis through the induction of p53/p21 and the initiation of mitochondrial system in human non-small cell lung cancer A549 cells. Eur J Pharmacol. 2007; 574(2-3):94-102.

37. Hu W, Kavanagh JJ. Anticancer therapy targeting the apoptotic pathway. Lancet Oncol. 2003;4(12):721-729.

38. Mao WP, Ye JL, Guan ZB, et al. Cadmium induces apoptosis in human embryonic kidney (HEK) 293 cells by caspase-dependent and -independent pathways acting on mitochondria. Toxicol In Vitro. 2007;21(3):343-354.

39. Zheng L, Zheng J, Wu LJ, Zhao YY. Julibroside J8-induced HeLa cell apoptosis through caspase pathway. J Asian Nat Prod Res. 2006; 8(5):457-465.

40. Pal S, Pal PB, Das J, Sil PC. Involvement of both intrinsic and extrinsic pathways in hepatoprotection of arjunolic acid against cadmium induced acute damage in vitro. Toxicology. 2011;283(2-3):129-139.
41. Zhang YH, Wu YL, Tashiro S, Onodera S, Ikejima T. Reactive oxygen species contribute to oridonin-induced apoptosis and autophagy in human cervical carcinoma HeLa cells. Acta Pharmacol Sin. 2011; 32(10):1266-1275.

42. Walensky LD. BCL-2 in the crosshairs: tipping the balance of life and death. Cell Death Differ. 2006;13(8):1339-1350.

43. Xiong A, Yang Z, Shen Y, Zhou J, Shen Q. Transcription factor STAT3 as a novel molecular target for cancer prevention. Cancers (Basel). 2014;6(2):926-957.

44. Slomovitz BM, Coleman RL. The PI3K/AKT/mTOR pathway as a therapeutic target in endometrial cancer. Clin Cancer Res. 2012;18(21): 5856-5864.

45. Mabuchi S, Kuroda H, Takahashi R, Sasano T. The PI3K/AKT/mTOR pathway as a therapeutic target in ovarian cancer. Gynecol Oncol. 2015; 137(1):173-179.

46. McRee AJ, Sanoff HK, Carlson C, Ivanova A, O’Neil BH. A phase I trial of mFOLFOX6 combined with the oral PI3K inhibitor BKM120 in patients with advanced refractory solid tumors. Invest New Drugs. 2015; 33(6):1225-1231.

47. Xia C, Bai X, Hou X, et al. Cryptotanshinone reverses cisplatin resistance of human lung carcinoma A549 cells through down-regulating Nrf2 pathway. Cell Physiol Biochem. 2015;37(2):816-824.

48. Hu T, To KK, Wang L, et al. Reversal of P-glycoprotein (P-gp) mediated multidrug resistance in colon cancer cells by cryptotanshinone and dihydrotanshinone of Salvia miltiorrhiza. Phytomedicine. 2014; 21(11):1264-1272
Drug Design, Development and Therapy

\section{Publish your work in this journal}

Drug Design, Development and Therapy is an international, peerreviewed open-access journal that spans the spectrum of drug design and development through to clinical applications. Clinical outcomes, patient safety, and programs for the development and effective, safe, and sustained use of medicines are the features of the journal, which

\section{Dovepress}

has also been accepted for indexing on PubMed Central. The manuscript management system is completely online and includes a very quick and fair peer-review system, which is all easy to use. Visit http://www.dovepress.com/testimonials.php to read real quotes from published authors. 